\title{
Development of novel formulations to enhance in vivo transdermal permeation of tocopherol
}

\author{
ALY H. NADA* \\ ABDELAZIM A. ZAGHLOUL \\ MOHSEN M. HEDAYA \\ IBRAHIM S. KHATTAB ${ }^{a}$ \\ Department of Pharmaceutics \\ Faculty of Pharmacy \\ Kuwait University, Kuwait \\ ${ }^{a}$ Current address: \\ Kuwaiti Saudi Pharmaceutical \\ Company (KSPICO), Kuwait
}

\begin{abstract}
Tocopherol represents a big challenge for transdermal permeation owing to its extreme hydrophobicity and large molecular mass. The aim of the present study was to develop alpha-tocopherol (T) topical formulations and evaluate their ex vivo and in vivo permeation. Franz diffusion cells were used for ex vivo permeation, and neonatal rats were used for in vivo permeation. Seven gel formulations and 21 liquid formulations were investigated for physical stability, viscosity and permeation of T. Analysis of T was performed by a validated HPLC method using a UV detector. The $e x$ vivo permeation from gel and emulsion formulations was very poor (0.001-0.015\%). Highest permeation was observed from monophasic liquid formulations containing dimethyl sulfoxide (DMSO), tocopheryl polyethylene glycols (TPGs), propylene glycol, ethanol and $9.5 \% \mathrm{~T}$. The in vivo results demonstrated higher retention in the epidermis compared to subcutaneous tissues, 1377 and $1.13 \mu \mathrm{g} \mathrm{g}^{-1}$, respectively. Increasing $\mathrm{T}$ concentration from 4.8 to $9.5 \%$ did not increase the amount permeated or \% of $\mathrm{T}$ retained. It was concluded that simple solutions of $\mathrm{T}$ in the presence of DMSO and TPGs were more promising systems for effective transdermal permeation compared to gel, emulsion or oleaginous systems.
\end{abstract}

Keywords: tocopherol, topical formulation, chemical analysis, ex vivo and in vivo, skin barrier

Human skin is the largest organ of the human body providing a natural protective barrier against penetration of toxic exogenous compounds/microbes and other environmental stress factors. In addition, it prevents loss of water and essential compounds from the human body and also provides a promising site for administration of drugs for local and/or systemic therapy (1-3). Due to constant exposure of the skin to various environmental factors, the skin is susceptible to oxidative stress, which occurs when the number of pro-oxidant species exceeds the number of antioxidant species $(4,5)$. $\alpha$-Tocopherol (T) plays a very important role in protecting skin and other organs, since it is the most active

\footnotetext{
* Correspondence; e-mail: alynada@hsc.edu.kw; alynada@gmail.com
} 
lipophilic antioxidant in biological membranes (6) and, together with ascorbic acid, constitutes the »antioxidant network « that protects the skin against oxidative damage (7). T may be the most important antioxidant because it is present in limited quantities, humans cannot synthesize it, it is readily depleted by UV radiation and other oxidative stresses such as ozone, and it is the dominant antioxidant responsible for protecting the stratum corneum lipids from oxidation $(5,8)$. Moreover, $\mathrm{T}$ plays different roles in the maintenance of skin physiological conditions. It has a moisturizing effect by limiting trans-epidermal water loss and seems to be able to regulate keratin turnover $(9,10)$. Therefore, $\mathrm{T}$ and its esters are among the best established ingredients in the over the counter (OTC) products for the delay/treatment of skin aging. However, results of activation of the prodrug T-acetate (TA) into the active form of $\mathrm{T}$ following topical administration are controversial and depend on the formulation factors and the skin model investigated (11).

Conventional means of applying drugs to the skin include vehicles such as ointments, creams, gels, and "passive" patch technology. Therefore, some dosage forms have been developed and/or modified to enhance the driving force of drug diffusion (thermodynamic activity) and/or increase the permeability of the skin. Such approaches include the use of penetration enhancers (12), supersaturated systems (13), prodrugs or metabolic approach (14-16), microemulsions (3), liposomes and other vesicles (17-19). Transdermal delivery of T represents a big challenge, since it exhibits extremely high lipophilic properties with $\log P$ values of $9.3-13.4$, as determined by calculation methods (20). Furthermore, permeation of $\mathrm{T}$ is particularly challenging because it is sparingly water-soluble and at the same time water is usually used as a major component of the receiver compartment (21).

In a previous work, we investigated some commercial cosmetic products containing T/TA. Results of in vivo permeation and hydrolysis of TA into T revealed that no conversion of acetate ester was observed in the neonatal rat skin model (22). Hence, it is not surprising that researchers are working in the direction of using the active form of vitamin $(\mathrm{T})$ rather than the prodrug (TA), aiming at improving its stability and permeation by optimizing the formulation factors and application of innovative technologies (23-25).

Consequently, the main objectives of the present study were to develop and optimize novel $\mathrm{T}$ formulations and to study drug permeation from such formulations through the neonatal rat skin (ex vivo and in vivo).

\section{EXPERIMENTAL}

\section{Chemicals}

Methanol, propylene glycol, Tween 80, dimethyl sulfoxide (DMSO-Merck KGaA, Germany); glycerol (Fisher Scientific UK Ltd, UK); isopropyl myristate 95 \% (Fluka Chemie, Switzerland); polyethylene glycol 400, Carbomer 934, methylcellulose, Span 80 (Loba Chemie, India); carboxymethylcellulose - NaC5013(CMC-Na), hydroxypropyl methylcellulose (HPMC) (Sigma Chemical Co, USA); Eudragit RL100 (Rohn Pharma Polymers, Germany); alpha-tocopherol (Sigma Aldrich Chemie $\mathrm{GmbH}$, Germany); dimethylformamide (DMF) (Riedel-de Haen Laborchemikalien, GmbH \& Co. KG, Germany); D- $\alpha$-tocopheryl polyethylene glycol 1000 - succinate (Courtesy of ISOCHEM S.A., France); purified water from Milli-Q synthesis, resistivity $18.2 \mathrm{M} \Omega \mathrm{cm}$ at $25^{\circ} \mathrm{C}$ (Millipore SAS, France). 


\section{Analysis of alpha-tocopherol}

The method involved a HPLC system with a variable wavelength and PDA detector (Waters 2690 Separations Module, USA), a disposable guard column C-18 and a RP Waters Symmetry C-18 column (26).

\section{Alpha-tocopherol formulation studies}

Gel formulations. - Seven gel formulations were prepared (GF1-GF7) using different gel-forming polymers (Methylcellulose, HPMC, Carbomer 934, Eudragit RL100, and CMC$\mathrm{Na}$ ). Some additives were included, such as ethanol, PEG 400, isopropyl myristate (ISPM), in addition to water. Each formula contained about $5 \% \mathrm{~T}$ and the composition of all formulations is summarized in Table I. Viscosity was assessed for each formulation and those showing good physical stability, without any sign of T separation, were further tested for ex vivo skin permeation.

Liquid formulations. - Twenty-one formulations (F1-F21) containing T (5-10 \%, V/V) in the form of emulsions (F1-F6) or solutions in various solvents or mixtures thereof (F7-F21) were prepared and tested for physical stability and skin permeation. Selected semi-polar and/or polar solvents/enhancers such as ethanol, DMF, DMSO, propylene glycol, PEG 400 and TPGs, in addition to Tween 80 and Span 80 as surfactants were used (Table II). The method of emulsion preparation was simple trituration of aqueous and oily phases, and other solution formulations were made by simple mixing of T with other ingredients. All experiments were carried out in containers protected from light by aluminum foils and in dimmed room. Formulations showing good physical stability were further tested for skin

Table I. Composition and viscosity of gel formulations (GF1-GF7)

\begin{tabular}{lccccccc}
\hline Ingredients/viscosity & GF1 & GF2 & GF3 & GF4 & GF5 & GF6 & GF7 \\
\hline Alpha-tocopherol & $0.5 \mathrm{~g}$ & $0.5 \mathrm{~g}$ & $0.5 \mathrm{~g}$ & $0.5 \mathrm{~g}$ & $0.5 \mathrm{~g}$ & $0.5 \mathrm{~g}$ & $0.5 \mathrm{~g}$ \\
NaCMC & $0.5 \mathrm{~g}$ & $0.5 \mathrm{~g}$ & $0.5 \mathrm{~g}$ & $0.5 \mathrm{~g}$ & $0.5 \mathrm{~g}$ & 0 & 0 \\
Eudragit RL100 & 0 & 0 & 0 & 0 & 0 & 5 & 5 \\
Carbomer 934 & $0.016 \mathrm{~g}$ & 0 & 0 & 0 & 0 & 0 & 0 \\
Water & $3.0 \mathrm{~mL}$ & $3.0 \mathrm{~mL}$ & $3.0 \mathrm{~mL}$ & $3.0 \mathrm{~mL}$ & $3.0 \mathrm{~mL}$ & 0 & 0 \\
Ethanol & $4.0 \mathrm{~mL}$ & $4.0 \mathrm{~mL}$ & $4.0 \mathrm{~mL}$ & $4.0 \mathrm{~mL}$ & $4.0 \mathrm{~mL}$ & $7.0 \mathrm{~mL}$ & $5.0 \mathrm{~mL}$ \\
PEG 400 & $3.0 \mathrm{~mL}$ & $3.0 \mathrm{~mL}$ & $2.0 \mathrm{~mL}$ & $1.0 \mathrm{~mL}$ & 0 & $3.0 \mathrm{~mL}$ & $5.0 \mathrm{~mL}$ \\
Isopropyl myristate & 0 & 0 & $1.0 \mathrm{~mL}$ & $2.0 \mathrm{~mL}$ & $3.0 \mathrm{~mL}$ & 0 & 0 \\
Viscosity, mPa s & $\mathrm{a}$ & $\mathrm{b}$ & 279.11 & $\mathrm{a}$ & $\mathrm{a}$ & 72.3 & 79.54 \\
\hline
\end{tabular}

\footnotetext{
${ }^{\text {a }}$ Complete phase separation
}

${ }^{\mathrm{b}}$ Droplet separation 


\begin{tabular}{|c|c|c|c|c|c|c|c|c|c|c|c|c|}
\hline Form. & 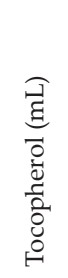 & 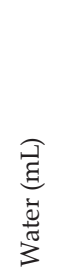 & 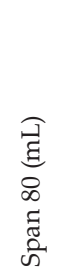 & 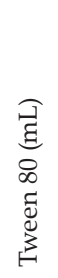 & 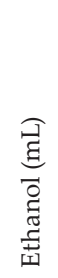 & 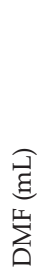 & 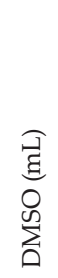 & 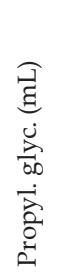 & 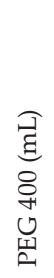 & $\begin{array}{l}\underset{\infty}{00} \\
0 \\
\tilde{E}\end{array}$ & 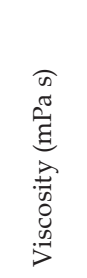 & 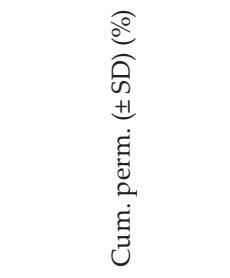 \\
\hline $\mathrm{F} 1^{\mathrm{c}}$ & 1 & 3 & 0.1 & 0.4 & 2.5 & 0 & 0 & 0 & 0 & 0 & 8.68 & $0.01527(0.001407)$ \\
\hline $\mathrm{F} 2^{\mathrm{c}}$ & 1 & 2.5 & 0.1 & 0.4 & 2.5 & 0 & 0 & 0 & 0 & 0 & 8.01 & $0.0123(0.003211)$ \\
\hline $\mathrm{F}^{\mathrm{c}}$ & 1 & 3 & 0.2 & 0.8 & 2.5 & 0 & 0 & 0 & 0 & 0 & 9.56 & $0.008503(0.002714)$ \\
\hline $\mathrm{F} 4^{\mathrm{c}}$ & 1 & 2.5 & 0.2 & 0.8 & 2.5 & 0 & 0 & 0 & 0 & 0 & 9.16 & $0.0141(0.001386)$ \\
\hline $\mathrm{F} 5^{\mathrm{b}}$ & 1 & 2 & 0.1 & 0.4 & 2.5 & 1 & 0 & 0 & 0 & 0 & 8.25 & $\mathrm{~b}$ \\
\hline $\mathrm{F} 6^{\mathrm{c}}$ & 1 & 2 & 0.1 & 0.4 & 2.5 & 0 & 1 & 0 & 0 & 0 & 7.95 & $0.0064(0.014658)$ \\
\hline $\mathrm{F} 7^{\mathrm{C}}$ & 1 & 0 & 0 & 0 & 1.5 & 0 & 1.5 & 0 & 6 & 0 & 24.96 & $0.008628(0.003117)$ \\
\hline $\mathrm{F} 8^{\mathrm{c}}$ & 1 & 0 & 0 & 0 & 2.5 & 0 & 1.5 & 5 & 0 & 0 & 22.35 & $0.026798(0.001052)$ \\
\hline $\mathrm{F}^{\mathrm{c}}$ & 1 & 0 & 0 & 0 & 2.5 & 0 & 3 & 5 & 0 & 0 & 22.03 & $0.017485(0.002979)$ \\
\hline $\mathrm{F} 10^{\mathrm{c}}$ & 1 & 0 & 0 & 0 & 2.5 & 0 & 5 & 5 & 0 & 0 & 21.2 & $0.028933(0.001487)$ \\
\hline $\mathrm{F} 11^{\mathrm{b}}$ & 1.35 & 0 & 0 & 0 & 2.5 & 0 & 5 & 5 & 0 & 0 & 22.04 & $\mathrm{~b}$ \\
\hline F12 & 1 & 0 & 0 & 0 & 2.5 & 0 & 5 & 1.5 & 0 & 0.5 & 21.24 & $0.050823(0.005798)$ \\
\hline F13 & 1 & 0 & 0 & 0 & 2.5 & 0 & 5 & 0 & 1.5 & 0.5 & 19.02 & $0.016073(0.007694)$ \\
\hline $\mathrm{F} 14^{\mathrm{a}}$ & 1 & 0 & 0 & 0 & 0 & 0 & 3.5 & 0 & 5.0 & 0.5 & a & a \\
\hline F15 & 0 & 0 & 0 & 0 & 2.5 & 0 & 5 & 1.5 & 0 & 0.5 & 19.11 & 0 \\
\hline F16 & 1 & 0 & 0 & 0 & 2.5 & 0 & 5 & 1.5 & 0 & 1.0 & 21.52 & $0.03857(0.013567)$ \\
\hline F17 & 1 & 0 & 0 & 0 & 2.5 & 0 & 5 & 1.5 & 0 & 1.5 & 21.07 & $0.049129(0.014958)$ \\
\hline F18 & 1 & 0 & 0 & 0 & 2.5 & 0 & 5 & 1.5 & 0 & 0.25 & 19.86 & 0.0510590 .012194 \\
\hline F19 & 0.5 & 0 & 0 & 0 & 2.5 & 0 & 5 & 1.5 & 0 & 0.5 & 20.22 & $0.149667(0.001452)$ \\
\hline F20 & 1 & 0 & 0 & 0 & 2.5 & 0 & 4.5 & 1.5 & 0 & 0.5 & 20.15 & $0.032041(0.002331)$ \\
\hline F21 & 1 & 0 & 0 & 0 & 2.0 & 0 & 4.5 & 2.0 & 0 & 0.5 & 22.54 & $0.022176(0.010471)$ \\
\hline
\end{tabular}

a Phase separation shortly after preparation

${ }^{\mathrm{b}}$ Phase separation after a few days of preparation

${ }^{c}$ Phase separation after 2 weeks of preparation

permeation. Chemical stability was checked after 3 months at room temperature and no appreciable loss in activity under these conditions was observed. Long term stability at different temperatures is planned. 


\section{Permeation study}

Ex vivo experiments. - Neonate rat epidermis (dorsal side) was used as a skin model. The rats used were Spraque Dawley, 2-3 days old and weighing 5-10 g. All experimental protocols were approved by the Animal Welfare Committee and complied with the Use of Laboratory Animals in the Health Sciences Center, Kuwait University.

Rats were euthanized using carbon dioxide asphyxiation before experiments and the epidermis was removed by a heat separation technique (27). The entire skin of neonate rats was soaked in water at $60^{\circ} \mathrm{C}$ for $60 \mathrm{~s}$, followed by careful removal of the epidermis. The epidermis so prepared was washed with water and examined for physical damage with a magnifying lens. The epidermis that was free from physical damage was used for the ex vivo permeation studies in vertical Franz diffusion cells (PermeGear Inc., USA). Epidermis was mounted between the compartments of diffusion cells, with the epidermal side facing the donor compartment and the subcutaneous side facing the receptor compartment. The effective diffusion area was $0.64 \mathrm{~cm}^{2}$ and the donor compartment volume was $1 \mathrm{~mL}$ while that of the receiver chamber was $5 \mathrm{~mL}$. The diffusion cell was maintained at $32{ }^{\circ} \mathrm{C}$. At predetermined time intervals, permeate samples were collected $(0.3 \mathrm{~mL})$ from the receptor compartment, diluted with methanol and assayed for T content by the HPLC method described earlier. The samples were replaced with an equal volume of receptor fluid maintained at $32{ }^{\circ} \mathrm{C}$.

Several fluids were initially tested in the receptor compartment, including buffer $\mathrm{pH}$ 7.2 and hydroalchoholic solutions with variable proportions of ethanol, and $50 \%$ ethanol in water was used as the receptor fluid throughout the study.

In vivo permeation experiments. - Two formulations (F12 and F19) were selected for the in vivo study based on their good physical stability and ex vivo permeation results. Each preparation was applied repeatedly onto the dorsal side $\left(7-8 \mathrm{~cm}^{2}\right)$ of neonatal rats. The two formulations were applied as $5 \mu \mathrm{L}$ every $30 \mathrm{~min}$ over 4 hours to allow evaporation of alcohol and retention on the skin without appreciable runoff. Excess material was removed with filter paper before skin removal. No assessment of the material remaining on the skin was done. Subsequently, the skin area used in the permeation study was removed and epidermis was separated (as described under the ex vivo permeation study) from the subcutaneous layer, crushed and extracted with successive volumes of methanol, made to 10 $\mathrm{mL}$, vortexed, and finally centrifuged before HPLC analysis of T retained in each skin layer. Triplicate experiments were run for each product under investigation. A sample of the supernatant was used for HPLC determination of T content as described earlier. The purpose of this procedure was to assess if any $\mathrm{T}$ was permeated through the epidermis and retained in deeper skin layers. Control experiments were run on naïve animals to determine naturally present $\mathrm{T}$.

Extraction efficiency of $\mathrm{T}$ was determined by successive local application of the standard solution of $\mathrm{T}$ in methanol (equivalent to the same concentration in the formulation) to each subcutaneous layer and epidermis of the neonatal rat skin, and treated in the same way as described above for the in vivo permeation of F12 and F19. Similarly, an individual skin layer was crushed, extracted with successive portions of methanol and made up to $10 \mathrm{~mL}$, centrifuged, and the amount of $\mathrm{T}$ extracted in each case was determined. Further, the amounts of $\mathrm{T}$ retained in the different parts, epidermis, subcutaneous layer, and full-thickness skin, were calculated and used for correction of the results obtained from test formulations. 


\section{RESULTS AND DISCUSSION}

\section{Formulation studies}

Gel formulations. - Table I shows the composition and viscosity of the prepared gel formulations. GF1, GF4 and GF5 showed phase separation, while GF2 showed droplet separation of oily T shortly after separation. Stable gel formulations (GF3, GF6 and GF7) were subjected to ex vivo permeation studies. These formulations exhibited either weak or no permeation even after 24 or 48 hours. This observation may be explained by the viscous nature of such formulations $(72-279 \mathrm{mPa}$ ), and by retarding the molecular diffusion and permeation of the large molecular mass $\mathrm{T}$. The presence of some oily ingredients such as isopropyl myristate in some gel formulations, although it is known to have permeation enhancing properties (12), more likely trapped the non-polar vitamin molecules and thereby retarded drug diffusion and permeation. Accordingly, it was decided to focus more on formulation of non-oily and monophasic liquid formulations with low viscosity.

Liquid formulations. - Liquid emulsion formulations of T (F1-F6) and simple solutions of T (F7-F11) exhibited low viscosity values (8-22 mPa s), compared to the gel formulations (Table II). All emulsion formulations showed relatively short-term stability compared to the other solution formulations, except in the case of F11which showed phase separation a few days after preparation (Table II). This last observation may be explained by the relatively higher T concentration (9.75 \%) compared to a similar one containing $7.4 \% \mathrm{~T}$ (F10).

Liquid monophasic formulations containing TPGs. - A set of liquid formulations (F12-F21) containing TPGs as solubilizer/enhancer were prepared (Table II). These formulations showed very good physical stability and no separation was observed after 6 months under the study conditions described earlier. TPGs were found to have good enhancing effect on permeation and in one study it was concluded that TPGs and ethanol synergistically enhanced griseofulvin permeation and drug retention in the skin (28). Therefore, F12-F21 formulations containing TPGs were further tested for ex vivo permeation and F12 and F19 were selected for the in vivo permeation study. The results are discussed under »Skin Permeation Study « hereafter. These formulations (F12-F21) were stable without signs of phase separation for more than 6 months at $25^{\circ} \mathrm{C}$. No appreciable loss of T content was detected under the same experimental conditions.

\section{Ex vivo permeation study}

Gel formulations. - Some stable gel formulations (GF3 and GF7) did not lead to any permeation of T, while GF6 showed slight permeation $(0.0137 \%)$ after $24 \mathrm{~h}$. This finding highlights the fact that although gel formulations are generally very popular and preferred by consumers, they hinder the permeation process due to their viscous nature (72$279 \mathrm{mPa}$ s), especially with a high molecular weight permeant like T.

Liquid emulsion formulations. - Formulations containing Span and Tween (F1-F6) exhibited low permeation after $24 \mathrm{~h}$, amounting to 0.0018 and $0.014 \%$ of the amount of $\mathrm{T}$ applied (Table II). This may be explained by retention of $\mathrm{T}$ in the formed micelles of mixed surfactants. 


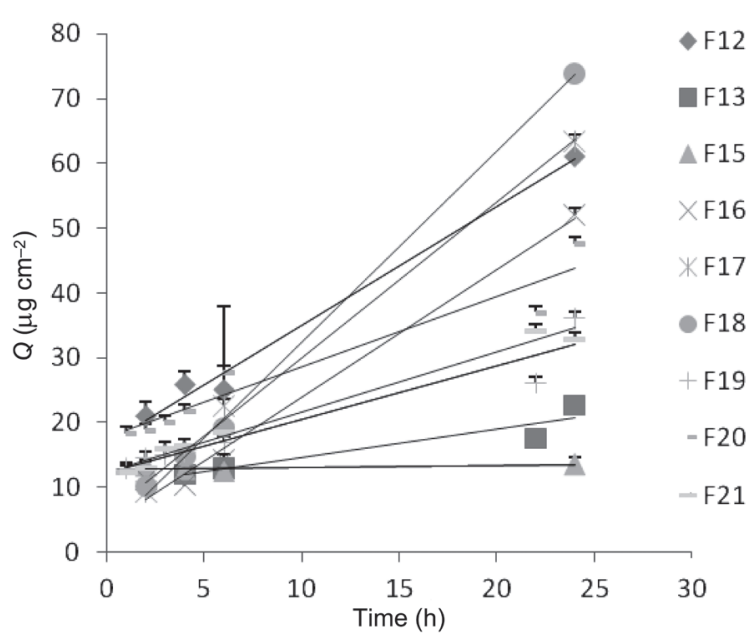

Fig. 1. Kinetic plots of the cumulative amount $\left(Q, \mu \mathrm{g} \mathrm{cm}{ }^{-2}\right)$ of alpha-tocopherol permeated from liquid formulations (F12-F21) vs. time (h) following the ex vivo study.

Monophasic liquid formulations. - Based on the observed negative effect of emulsion systems on physical stability and $\mathrm{T}$ permeation, the following solution formulations were investigated. Table II summarizes the composition of these formulations (F7-F21), along with their viscosity and \%-cumulative permeation after $24 \mathrm{~h}$. Inclusion of DMSO and replacement of water (in F1-F6) with PEG 400 (F8-F10) or propylene glycol (F7) resulted in better permeation. The calculated \%-permeation range was $0.017-0.029 \%$ (F8-F10) and 0.019 $\%$ (F7). Furthermore, inclusion of TPGs improved the \%-permeation, amounting to $0.05 \%$ (F12) and $0.149 \%$ (F19) after $24 \mathrm{~h}$. TPGs alone did not contribute to T permeation results, as evidenced by the T-free formulation (F15) where no T permeation was detected. The relatively higher permeation observed with TPG formulations may be explained in terms of a synergistic enhancing permeation of DMSO and TPGs. In addition, the synergistic effect of TPGs and ethanol on enhancing griseofulvin penetration was previously reported (28). Ethanol-free formulation (F14) showed phase separation and was therefore dropped from the permeation study. Further, the cumulative amounts of $\mathrm{T}$ permeated at each time interval after starting the study were calculated according to Fick's first law of diffusion and were further used to construct the permeation curves (Fig. 1), as discussed hereafter.

\section{Kinetic analysis of ex vivo permeation data}

The trans-membrane diffusion profile was determined by the analysis of the cumulative amount of $\mathrm{T}$ in the receptor compartment after predetermined time intervals up to 24 h. Assuming a steady state condition, the diffusion process follows Fick's first law:

$$
\mathrm{d} Q / \mathrm{d} t=P_{\mathrm{S}}\left(C_{\mathrm{D}}-C_{\mathrm{R}}\right)
$$

where $P_{\mathrm{S}}(\mathrm{cm} / \mathrm{h})$ is the skin permeability coefficient and $C_{\mathrm{D}}$ and $C_{\mathrm{R}}\left(\mathrm{g} \mathrm{cm}^{-3}\right)$ are drug concentrations in the donor and receptor chambers, respectively, while $Q$ is the cumulative amount diffused through a unit of skin surface $\left(\mu \mathrm{g} \mathrm{cm}^{-2}\right)$. 
Integration of $E q$. (1) gives:

$$
Q=P_{\mathrm{S}}\left(C_{\mathrm{D}}-C_{\mathrm{R}}\right) t
$$

Fig. 1 demonstrates the linear relationships between $Q$ and time, assuming infinite dose conditions ( $\mathrm{CD} \gg \mathrm{CR}$ ).

The flux $J\left(\mu \mathrm{g} \mathrm{cm}^{-2} \mathrm{~h}^{-1}\right)$ calculated from the slope of $Q$ vs. time plots during the steady state of the kinetic study afforded the skin permeability coefficient, Eq. (3).

$$
P_{\mathrm{s}}=\frac{J}{C_{\mathrm{D}}}
$$

The permeability coefficient and flux of different formulations were calculated and the values are summarized in Table IV.

The reported flux values for T in this study $\left(0.437-2.946 \mu \mathrm{g} \mathrm{cm}^{-2} \mathrm{~h}^{-1}\right)$, although relatively low, are higher than those reported in a previous work, being $1.3 \times 10^{-3}$ and $9.74 \times$ $10^{-3} \mathrm{\mu g} \mathrm{cm}^{-2} \mathrm{~h}^{-1}$ from a W/O and O/W emulsion, respectively (29). In addition, the observed flux values in our formulations were much higher than the reported corresponding values through a reconstructed human epidermis (RHE) membrane, where the reported values were $\approx 0$ for each type of tested emulsions (29).

Further, the values of permeation coefficients observed in the present study $(4.83 \times$ $10^{-6}-3.18 \times 10^{-5} \mathrm{~cm} \mathrm{~h}^{-1}$ ) were similar to those determined by Gabbanini et al. through a synthetic membrane $\left(4 \times 10^{-5}\right.$ and $3 \times 10^{-4} \mathrm{~cm} \mathrm{~h}^{-1}$ from W/O and O/W emulsions, respectively) (29). Also, the permeation coefficients from the tested emulsions by the same authors using the RHE membrane were found to $b e \approx 0$, which is lower than the values determined in our investigations $\left(4.83 \times 10^{-6}-3.18 \times 10^{-5} \mathrm{~cm} \mathrm{~h}^{-1}\right)$ (Table IV).

On the other hand, the flux and permeation coefficient values for water soluble vitamins reported by Gabbanini et al. for ascorbic acid and pyridoxine were by far higher than those reported for the investigated fat-soluble vitamins $\alpha$-tocopherol and retinol acetate (29).

The afore-mentioned results and previous data reported from this laboratory (30) confirm the challenging nature of transdermal permeation of T/TA owing to their exceptionally high lipophilic nature and large molecular mass required for optimum transdermal permeation.

\section{In vivo permeation}

The amount of $\mathrm{T}$ along with the \% retained in the epidermis, subcutaneous layer, and full-thickness skin after repeated application of two formulations (F12 and F19) are summarized in Table V. The amount retained in the full thickness skin was calculated by adding that retained in the epidermis to that found in the subcutaneous layer. Corrected values of permeation data were calculated, based on the determined extraction efficiency from each of the epidermis, subcutaneous layer and full skin (Table IV). The results demonstrate higher retention properties of the epidermal layer compared to subcutaneous tissues. The difference is more appreciable when we calculate the amount of $\mathrm{T}$ retained per $\mathrm{g}$ of skin layers, being $1377 \mu \mathrm{g} \mathrm{g}^{-1}$ and $1.13 \mu \mathrm{g} \mathrm{g}^{-1}$ for the epidermal and subcutaneous layers, respectively. The amounts and \% of T retained by each skin layer after application of F12 
A. H. Nada et al.: Development of novel formulations to enhance in vivo transdermal permeation of tocopherol, Acta Pharm. 64 (2014) 299-309.

Table III. Permeation coefficients $\left(\mathrm{P}_{\mathrm{s}}\right)$ and flux $(\mathrm{J})$ values of alpha-tocopherol $(\mathrm{T})$ from monophasic-TPG formulations (F12-F21) following the ex vivo study

\begin{tabular}{lccc}
\hline Formulation & $J$, slope $\left(\mu \mathrm{g} \mathrm{cm}^{-2} \mathrm{~h}^{-1}\right)$ & $C_{\mathrm{d}}\left(\mu \mathrm{g} \mathrm{cm}^{-3}\right)$ & $P_{\mathrm{s}}\left(\mathrm{cm} \mathrm{h}^{-1}\right)$ \\
\hline F12 & 1.8297 & 90470 & $2.02 \mathrm{E}-05$ \\
F13 & 0.4374 & 90470 & $4.83 \mathrm{E}-06$ \\
F14 & - & - & - \\
F15 & - & - & - \\
F16 & 1.9749 & 86360 & $2.29 \mathrm{E}-05$ \\
F17 & 2.4148 & 82600 & $2.92 \mathrm{E}-05$ \\
F18 & 2.9461 & 92680 & $3.18 \mathrm{E}-05$ \\
F19 & 1.0026 & 47500 & $2.11 \mathrm{E}-05$ \\
F20 & 1.2837 & 95000 & $1.35 \mathrm{E}-05$ \\
F21 & 1.0220 & 95000 & $1.08 \mathrm{E}-05$ \\
\hline
\end{tabular}

a Complete phase separation

${ }^{\mathrm{b}}$ Alpha-tocopherol $=0.0 \%$

Table IV. In vivo permeation of alpha-tocopherol from formulations F12 and F19

\begin{tabular}{|c|c|c|c|c|c|c|c|c|c|c|c|c|}
\hline \multirow{2}{*}{$\begin{array}{l}\text { Alpha- } \\
\text { tocopherol }\end{array}$} & \multicolumn{3}{|c|}{$\begin{array}{c}\text { Amount retained } \\
(\mu \mathrm{g})\end{array}$} & \multicolumn{3}{|c|}{$\begin{array}{l}\text { Amount retained } \\
\qquad\left(\mu \mathrm{g} \mathrm{g}^{-1}\right)\end{array}$} & \multicolumn{3}{|c|}{$\begin{array}{l}\text { Tocopherol } \\
\text { retained (\%) }\end{array}$} & \multicolumn{3}{|c|}{$\begin{array}{l}\text { Corrected \% } \\
\text { retained }\end{array}$} \\
\hline & $\mathrm{EP}^{\mathrm{a}}$ & $\mathrm{ST}^{\mathrm{b}}$ & F. Skin ${ }^{c}$ & $\mathrm{EP}$ & ST & FS & $\mathrm{EP}$ & ST & F. Skin & $\mathrm{EP}$ & ST & F. Skin \\
\hline \multicolumn{13}{|c|}{ F12 } \\
\hline Average & 259.69 & 22.57 & 282.26 & 1377.66 & 39.07 & 1416.73 & 8.92 & 1.13 & 10.04 & 12.71 & 2.14 & 16.33 \\
\hline$\pm \mathrm{SD}$ & 68.13 & 11.58 & 77.78 & 371.74 & 0.58 & 379.60 & 2.41 & 0.58 & 2.93 & & & \\
\hline \multicolumn{13}{|c|}{ F19 } \\
\hline Average & 146.04 & 55.19 & 201.23 & 675.56 & 77.94 & 753.51 & 7.69 & 2.90 & 10.58 & 10.97 & 5.55 & 17.34 \\
\hline$\pm \mathrm{SD}$ & 30.77 & 10.64 & 28.63 & 132.58 & 3.51 & 135.60 & 1.62 & 0.56 & 1.51 & & & \\
\hline
\end{tabular}

${ }^{a}$ Epidermis

b Subcutaneous tissues

${ }^{\mathrm{c}}$ Full-thickness skin

and F19 were very close, indicating that increasing T concentration from $5.0 \%$ (F19) to $9.5 \%$ (F12) did not increase the amount of T permeated or its \% retained. Although these values seem relatively low, they are nevertheless higher than the permeation results reported in previous studies $(22,29)$. However, more investigations are necessary to further enhance the transdermal permeation of $\mathrm{T}$ for better therapeutic and cosmetic outcomes. 


\section{CONCLUSIONS}

Use of hydrophilic gel-forming polymers and emulsions for transdermal delivery of alpha-tocopherol was found to be inappropriate. Monophasic systems containing ethanol, DMF, DMSO as solvents and/or enhancers, in addition to TPGs as enhancer, were found to be the best formulations in this study. In vivo data demonstrated that the epidermis is the main site for the retention of $\mathrm{T}$, and increasing $\mathrm{T}$ concentration did not result in better permeation or retention. Although the \%-retention values of $\mathrm{T}$ in full skin seem relatively low (16.33-17.34 \%), they are higher than the permeation results reported in previous studies. The data generated from the present work highlight the challenging nature of $\mathrm{T}$ for transdermal delivery due to its extreme hydrophobic properties and high molecular mass. Further research is needed in this area to achieve the desirable therapeutic and cosmetic objectives for topical administration of $\mathrm{T}$.

Acknowledgements. - This work was supported by the Kuwait University, Research Grant No. [PP01/09]. The authors are grateful to the Department of Pharmaceutics support staff for their indispensable technical assistance. The supply and care of animals by the Animal Resource Center, Health Sciences Center, Kuwait University, is highly appreciated.

\section{REFERENCES}

1. W. Ting, C. Vest and R. Sontheimer, Review of traditional and novel modalities that enhance the permeability of local therapeutics across the stratum corneum, Int. J. Dermatol. 43 (2004) 538-547; DOI: 10.1111/j.1365-4632.2004.02147.x.

2. M. B. Brown, G. P. Martin, S. A. Jones and F. K. Akomeah, Dermal and transdermal drug delivery systems:currentand future prospects, Drug Deliv. 13(2006)175-187; DOI:10.1080/10717540500455975.

3. A. A. Date and V. B. Patravale, Microemulsions: applications in transdermal and dermal delivery, Crit. Rev. Ther. Drug Carrier Syst. 24 (2007) 547-596; DOI: 10.1615/CritRevTherDrugCarrierSyst.v24. i6.20.

4 K. J. Trouba, H. K. Hamadeh, R. P. Amin and D. R. Germolec, Oxidative stress and its role in skin disease, Antioxid. Redox Signal. 4 (2002) 665-673; DOI: 10.1089/15230860260220175.

5. A. Tavakkol, Z. Nabi, N. Soliman and T. G. Polefka, Delivery of vitamin E to the skin by a novel liquid skin cleanser: Comparison of topical versus oral supplementation, J. Cosmet. Sci. 55 (2004) 177-187; PMID 15131729.

6. X. Wang and P. J. Quinn, The location and function of vitamin E in membranes (review), Mol. Membr. Biol.17 (2000) 143-156; DOI: 10.1080/09687680010000311.

7. J. J. Thiele, C. Schroeter, S. N. Hsieh, M. Podda and L. Packer, The antioxidant network of the stratum corneum, CurrProblDermatol. 29 (2001) 26-42; DOI: 10.1159/000060651.

8. F. Nachbar and H. C. Korting, The role of vitamin E in normal and damaged skin, J. Mol. Med. 73 (1995) 7-17; DOI: 10.1007/BF00203614.

9. F. Marra, C. Ostacolo, S. Laneri, A. Bernardi and P. Santi, Synthesis, hydrolysis, and skin retention of amino acid esters of alpha-tocopherol, J. Pharm. Sci. 98 (2009) 2364-2376; DOI: 10.1002/jps.21608.

10. E. S. Krol, K. A. Kramer-Stickland and D. C. Liebler, Photoprotective actions of topically applied vitamin E, Drug Met. Rev. 32 (2000) 413-420; DOI: 101081DMR100102343.

11. M. Rangarajan and J. L. Zatz, Effect of formulation on the delivery and metabolism of alpha-tocopheryl acetate, J. Cosmet. Sci. 52 (2001) 225-236; PMID 11479655.

12. A. C. Williams and B.W. Barry, Penetration enhancers, Adv. Drug Deliv. Rev. 56 (2004) 603-618; DOI: 10.1016/j.addr.2003.10.025. 
13. S.R. Pinnell. Cutaneous photodamage, oxidative stress, and topical antioxidant protection, J. Am. Acad. Dermatol. 48 (2003) 1-19; DOI: 10.1067/mjd.2003.16.

14. J. C. Tsai, R. H. Guy, C. R. Thornfeldt, W. N. Gao, K. R. Feingold and P. M. Elias. Metabolic approaches to enhance transdermal drug delivery. 1. Effect of lipid synthesis inhibitors, J. Pharm.Sci. 85 (1996) 643-648; DOI: 10.1021/js950219p.

15. P. M. Elias, K. R. Feingold and J. C. Tsai, Metabolic Approach to Transdermal Drug Delivery, in Transdermal Drug Delivery (Eds. R.H. Guy, J. Hadgraft), $2^{\text {nd }}$ ed. Marcel Dekker, New York 2003, pp. 285-383; DOI: 10.1007/978-3-642-00477-3_13.

16. M. Rangarajan and J. L. Zatz, Kinetics of permeation and metabolism of alpha-tocopherol and alpha-tocopheryl acetate in micro-Yucatan pig skin, J. Cosmet. Sci. 52 (2001) 35-50.

17. B. Godin and E. Touitou, Ethosomes: New prospects in transdermal delivery, Crit. Rev. Ther. Drug Carrier Syst. 20 (2003) 63-102; DOI: 10.1615/CritRevTherDrugCarrierSyst.v20.i1.20.

18. E. Yenilmez and Y. Yazan, Release of vitamin E from different topical colloidal delivery systems and their in vitro-in vivo evaluation, Turk. J. Pharm. Sci. 7 (2010) 167-187.

19. E. Yenilmez, E. BaŞaran and Y. Yazan, Release characteristics of vitamin E incorporated chitosan microspheres and in vitro-in vivo evaluation for topical application, Carbohyd. Polym. 84 (2011) 807-811; DOI: 10.1016/j.carbpol.2010.07.002.

20 A. Niestroj, Comparison of methods for calculation of the partition coefficients of selected tocopherols, J. Planar. Chromatogr. 20 (2007) 483-486; DOI: 10.1556/JPC.20.2007.6.15.

21. H. Mahamongkol, R. A. Bellantone, G. Stagni and F. M. Plakogiannis, Permeation study of five formulations of alpha-tocopherol acetate through human cadaver skin, J. Cosmet. Sci. 56 (2005) 91-103; DOI: 10.1111/j.0142-5463.2005.00275_4.x.

22. A. Nada, Y. S. R. Krishnaiah, A. Zaghloul and I. Khattab, In vitro and in vivo permeation of vitamin E and vitamin E acetate from cosmetic formulations, Med. Princ. Pract. 20 (2011) 509-513; DOI: $10.1159 / 000329883$

23. R. Cassano, S. Trombino, R. Muzzalupo, L. Tavano and N. Picci, A novel dextran hydrogel linking trans-ferulic acid for the stabilization and transdermal delivery of vitamin E, Eur. J. Pharm. Biopharm. 72 (2009) 232-238; DOI: 10.1016/j.ejpb.2008.10.003.

24. X. Wu and R. H. Guy, Applications of nanoparticles in topical drug delivery and in cosmetics, J. Drug Del. Sci. Tech. 19 (2009) 371-384.

25. B. Rozman, M. Gosenca, M. Gasperlin, K. Padois and F. Falson, Dual influence of colloidal silica on skin deposition of vitamins $\mathrm{C}$ and $\mathrm{E}$ simultaneously incorporated in topical microemulsions, Drug Dev. Ind. Pharm. 36 (2010) 852-860; DOI: 10.3109/03639040903541187.

26. A. Nada, Y. S. R. Krishnaiah, A. Zaghloul and I. Khattab, Analysis of vitamin E in commercial cosmetic preparations by HPLC, J. Cosmet. Sci. 61 (2010) 353-365; PMID 20939975.

27. K. Zhao and J. Singh, In vitro percutaneous absorption enhancement of propranolol hydrochloride through porcine epidermis by terpenes/ethanol, J. Control. Release 62 (1999) 359-366; DOI: 10.1016/S0168-3659(99)00171-6.

28. N. Aggarwal, S. Goindi and S. D. Mehta, Preparation and evaluation of dermal delivery system of griseofulvin containing vitamin E-TPGS as penetration enhancer, AAPS Pharm. Sci. Tech. 13 (2012) 67-74; DOI: 10.1208/s12249-011-9722-y.

29. S. Gabbanini, R. Matera, C. Beltramini, A. Minghetti and L. Valgimigli, Analysis of in vitro release through reconstructed human epidermis and synthetic membranes of multi-vitamins from cosmetic formulations, J. Pharm. Biomed. Anal. 52 (2010) 461-467; DOI: 10.1016/j.jpba.2010.01.029. 